\title{
A New Modification of the Pomeranz-Fritsch Reaction
}

\author{
Fabrício Fredo Naciuk, Julio Cesar Milan, and Paulo Miranda* \\ Instituto de Química, Universidade Estadual de Campinas, SP \\ *miranda@iqm.unicamp.br
}

Keywords: Pomeranz-Fritsch reaction, trifluoroacetic acid, alkoxyisoquinolines

\section{INTRODUCTION}

Pomeranz-Fritsch reaction is a well known strategy to generate isoquinoline nucleus, despite its drawbacks. It is a substrate dependent reaction and alkoxylated substrates may react in particular ways producing undesired products. Depending on alkoxy group position cyclization rate is reduced and intermolecular reactions, solvolysis or ether deprotection begin to occur.

Some modifications of the original procedure were introduced in the past by Bobbit ${ }^{1}$ and Jackson ${ }^{2}$ but, although they improved the yield for most of substrates, these variants still show dependence on pattern substitution.

\section{RESULTS AND DISCUSSION}

In this work we prepared 5,8-dimethoxyisoquinoline (1) using Pomeranz-Fritsch based reactions. The starting material (2) has two methoxy groups in critical positions, both depleting the course of cyclization step. Methoxy group at position 2 has electronic influence and methoxy group at position 5 has steric influence.

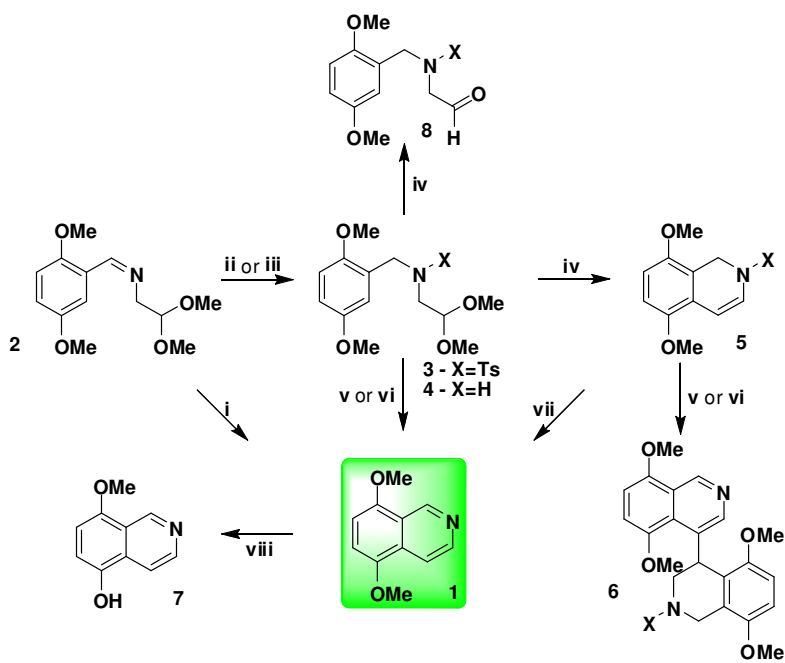

i) concd $\mathrm{H}_{2} \mathrm{SO}_{4}$; ii) a] $\mathrm{NaBH}_{4}, \mathrm{MeOH}$; b] TsCl, $\mathrm{Na}_{2} \mathrm{CO}_{3}$, DCM to 3 ; iii) $\mathrm{NaBH}_{4}$, MeOH to 4; iv) $\mathrm{HCl}$ 6M/dioxane v) $\mathrm{H}_{2} \mathrm{SO}_{4} /$ dioxane/EtOH; vi) $\mathrm{CF}_{3} \mathrm{COOH}, \mathrm{O}_{2}$; vii) $t$-BuOH/t-BuOK; viii) concd $\mathrm{HCl}$, EtOH $95 \%$.

Figure 1. Pomeranz-Fritsch reaction (I) and Jackson (ii) and Bobbit variations (iii).

Used conditions are shown in figure 1 and table 1. Jackson variation (ii) as well as Bobbit variation (iii) showed low yields when applied to substrate 2. We observed formation of concurrent products as aldehyde $^{3} 8$ and dimer $^{4} \mathbf{6}$, as well as incomplete transformation product $^{3}(5)$ instead of the desired one (1), which generated the isoquinoline only after treatment with $t$-BuOK/t-BuOH $(v i i){ }^{3}$ Nevertheless the use of more drastic reaction conditions leads to ether deprotection products such as $7^{5}$ In order to circumvent all these drawbacks we investigate the use of a less nucleophilic counterion to reduce the ether deprotection ( viii), and higher dilution to avoid dimerization ( $v$ or $v i$ ). The addition of alcohols as cosolvents to minimize acetal deprotection was also investigated and we find that ethylene glycol and $\mathrm{H}_{2} \mathrm{SO}_{4}$ (entry 7 at Table 1 ) was the most effective condition.

Table 1. Selected conditions used in Pomeranz-Fritsch based reactions of compound 2 .

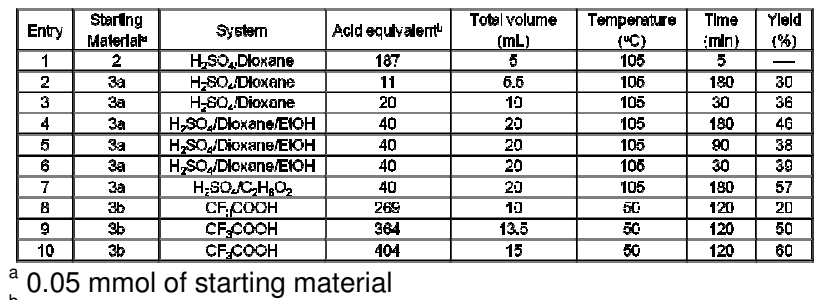

${ }^{\mathrm{b}}$ Equivalents in relation to starting material

\section{CONCLUSION}

We have studied Pomeranz-Fritsch based reactions of a well known low reactive substrate (2). Careful tuning of concentrations and conditions allowed yield improvement from less than $15 \%$ to up to $60 \%$. We confirmed the previous statements: dilution, counterion nucleophilicity and ketal deprotection have crucial importance on reaction course of less reactive substrates.

\section{ACKNOWLEDGEMENTS}

The authors acknowledge CNPq and FAPESP 2009/51602-5 for the financial support.

\section{REFERENCES}

${ }^{1}$ Bobbit, J. M.; Kiely, J. M.; Khana, K. L; Ebermann, R. J. Org. Chem. $1965,30,2247$.

${ }^{2}$ Birch, A. J.; Jackson, A. H.; Shannon, P. V. R. J. Chem. Soc., Perkin Trans 1 1974, 2185.

${ }^{3}$ Bianchi, D. A.; Cipulli, M. A.; Kaufman, T. S. Eur. J. Org. Chem. 2003, 4731

${ }^{4}$ Armengol, M.; Helliwell, M.; Joule, J. A. Arkivoc 2000, v, 832.

${ }^{5}$ Li, J.; Kung, D. W.; Griffith, D. A. Tetrahedron Lett. 2010, 51, 3876. 